Boletín de la Sociedad Geológica Mexicana

VOLUMEN 67, NÚM. 2, 2015, P. 299-313

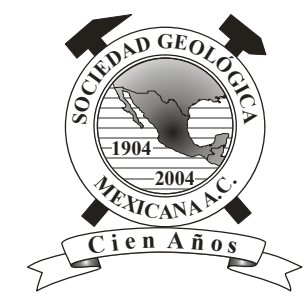

\title{
Determinación de los procesos hidrogeoquímicos participantes en la composición del agua de las fuentes de abastecimiento a pobladores de la delegación Iztapalapa, D.F., México
}

\author{
Eloísa Domínguez Mariani ${ }^{1, *}$, Carlos Vargas Cabrera ${ }^{1,2}$, Fredy Martínez Mijangos ${ }^{2}$, \\ Eugenio Gómez Reyes ${ }^{3}$, Oscar Monroy Hermosillo ${ }^{3}$ \\ ${ }^{1}$ Universidad Autónoma Metropolitana, Unidad Lerma, Av. de las Garzas 10, Col. El Panteón, Lerma de Villada, Municipio de Lerma, \\ Estado de México, 52005, México. \\ ${ }^{2}$ Centro para la Sustentabilidad Incalli Ixcahuicopa, Centli, Carretera Tlalmanalco-San Rafael km 1.2, San Juan Atzacualoya, \\ Tlalmanalco, Estado de México, 56720, México. \\ ${ }^{3}$ Universidad Autónoma Metropolitana, Unidad Iztapalapa, Rafael Atlixco No. 186, Col. Vicentina, Iztapalapa, D.F., 09340, México. \\ *eloisadm@yahoo.com.mx
}

\begin{abstract}
Resumen
Los problemas para el abastecimiento de agua a pobladores de la Cuenca de México han sido una constante, agravándose especialmente en la delegación Iztapalapa con la extracción intensiva del agua subterránea y el descenso de niveles piezométricos. En el agua subterránea obtenida de 17 pozos, los parámetros fisicoquímicos más significativos tienen las siguientes concentraciones: $\mathrm{Fe}^{2+}(0.004$ - $0.6 \mathrm{mg} / \mathrm{L}), \mathrm{Mn}^{2+}(0.003-0.96 \mathrm{mg} / \mathrm{L}), \mathrm{Na}^{+}(91-598 \mathrm{mg} / \mathrm{L})$ y Cl${ }^{-}(59.5-372 \mathrm{mg} / \mathrm{L})$, demanda química de oxígeno (DQO) (3.8 - 63.8 $\mathrm{mg} / \mathrm{L})$ y conductividad eléctrica (CE) $(620-2503 \mu \mathrm{S} / \mathrm{cm})$ además de turbiedad y mal aroma. Algunos de los anteriores parámetros están fuera de la norma mexicana para agua potable en algunos de los puntos muestreados. Se determinaron los siguientes procesos hidrogeoquímicos: mezcla entre diferentes componentes de flujo subterráneo inducidas por bombeo intensivo en la propia delegación, con agua salobre del acuitardo sobreyacente. El efecto neto es el incremento del contenido iónico del agua subterránea hasta la tendencia a la precipitación de minerales ferromagnesianos, carbonatos, fosfatos y silicatos en la red de abastecimiento, y turbidez del agua extraída. Lo anterior se demostró mediante el cálculo de índices de saturación con el software PHREEQC. Se tienen condiciones reductoras a causa de la oxidación de materia orgánica y consecuentemente reducción de sulfatos, denitrificación y presencia de gases como $\mathrm{CO}_{2} \mathrm{y} \mathrm{H}_{2} \mathrm{~S}$, este último asociado con corrosión de la red de agua potable y mal aroma.
\end{abstract}

Palabras clave: calidad del agua, hidrogeoquímica, explotación intensiva del agua, hierro, salinización, reducción de sulfatos.

\begin{abstract}
The water supply issues for Basin of Mexico residents have been constant; recently they have increased in Iztapalapa because of the groundwater withdrawal. The most significant concentrations, obtained from 17 wells, were: $\mathrm{Fe}^{2+}(0.004-0.6 \mathrm{mg} / \mathrm{L}), \mathrm{Mn}^{2+}$ $(0.003-0.96 \mathrm{mg} / \mathrm{L}), \mathrm{Na}^{+}(91-598 \mathrm{mg} / \mathrm{L})$ and $\mathrm{Cl}^{-}(59.5-372 \mathrm{mg} / \mathrm{L}), \mathrm{COD}(3-63.8 \mathrm{mg} / \mathrm{L})$ and specific conductivity $(620-2503 \mu \mathrm{S} /$ $\mathrm{cm})$, in addition with turbidity and bad odour. The following hydrogeochemical processes were determined: mixing between different groundwater flow components induced by heavy pumping, and brackish water of overlying aquitard, increasing of the ionic content of groundwater until the precipitation of minerals like carbonates, phosphates and silicates on supply network and turbidity of the water extracted. This was demonstrated by calculating saturation index with the software PHREEQC. Redox conditions are consequence of organic matter oxidation, and therefore sulfate reduction, denitrification and presence of gases such as $\mathrm{CO}_{2}$ and $\mathrm{H}_{2} \mathrm{~S}$, the latter associated with corrosion in the drinking water network.
\end{abstract}


Keywords: water quality, hydrochemistry, water extraction, iron, salinization, sulfate reduction.

\section{Introducción}

El agua subterránea en general se consideró por mucho tiempo de buena calidad debido a que se encuentra relativamente protegida de eventos contaminantes producidos en superficie, sin considerar que se ubican actividades potencialmente contaminantes en la superficie de acuíferos vulnerables (Foster et al., 2007). Como es el caso de acuíferos en materiales geológicos fracturados, el riesgo es mayor debido al potencial de infiltración relativamente rápido, sin oportunidad de retención de los componentes fisicoquímicos por parte del medio. Adicionalmente, la calidad del agua subterránea puede deteriorarse debido al bombeo intensivo que puede inducir el flujo de agua de mayor contenido iónico desde gran distancia.

La estratigrafía del acuífero de la Ciudad de México es descrita como una potente secuencia de materiales volcánicos con una importante cobertura de sedimentos lacustres. Los más antiguos comprenden materiales clásticos del Eoceno, basaltos y riolitas del Oligoceno y andesitas del Mioceno, cuya potencia en conjunto es de $300 \mathrm{~m}$; sobreyacen a depósitos del Plioceno inferior que incluyen materiales lacustres y piroclásticos (con un espesor de $600 \mathrm{~m}$ ). A continuación se presentan basaltos-andesitas $\mathrm{y}$ andesitas plio-cuaternarias, andesitas pliocénicas y piroclastos plio-cuaternarios en las elevaciones topográficas $\mathrm{y}$ en los depósitos lacustres que se comportan como un acuitardo (con espesor de $1000 \mathrm{~m}$ ), mientras que los depósitos del Cuaternario-Reciente comprenden $600 \mathrm{~m}$ de depósitos aluviales y fluviales (Edmunds et al., 2002).

Por lo anterior, la composición del agua subterránea estará asociada principalmente al tiempo de interacción con materiales volcánicos, debido a que el principal acuífero es el de tipo granular y en segundo lugar, el ubicado en la unidad volcánica. Edmunds et al. (2002) definieron la asociación entre el flujo natural procedente de las montañas circundantes hacia el centro del valle y los cambios hidrogeoquímicos en razón de las líneas de flujo, sin evidencia de paso de componentes inorgánicos desde el acuitardo o desde fuentes superficiales. Sin embargo, se estima que la extracción intensiva y los efectos asociados como el fracturamiento y la subsidencia, han influido en la variación de la composición del agua subterránea de algunas pociones de la cuenca. Tal es el caso muy notorio, de la mala calidad del agua subterránea que procede de pozos ubicados en la delegación Iztapalapa, que de manera general, presenta coloración café pálida a muy intensa y aroma fétido, lo que imposibilita el consumo de manera confiable. El objetivo de este artículo es presentar el análisis de la composición del agua que se extrae de pozos ubicados en la delegación
Iztapalapa mediante parámetros fisicoquímicos, para definir los probables procesos hidrogeoquímicos que la originan, tomando en cuenta la conformación geológica de la región y la dinámica de la extracción intensiva que se lleva a cabo en la zona.

\section{Descripción del área de trabajo}

La delegación Iztapalapa es una de las 16 que conforman el Distrito Federal, se encuentra localizada al oriente, en los límites con el Estado de México (Figura 1). Por su ubicación genera una interrelación de servicios de equipamiento, transporte y actividad cotidiana con los municipios de Nezahualcóyotl, Los Reyes-La Paz y Chalco-Solidaridad (Arango-Durán y Lara-Medina, 2005). Ocupa un área de $114 \mathrm{~km}^{2}$ donde se encuentran asentados 1815796 habitantes (INEGI, 2015) por lo que es la delegación con mayor densidad de población en el Distrito Federal con 16 hab/ $\mathrm{m}^{2}$. Es de hacer notar que el $92.7 \%$ del área se encuentra fuertemente urbanizada y sólo cuenta con el $7.3 \%$ son áreas verdes (DI, 2007). Se ubican dentro de sus límites: el Cerro de la Estrella (2462 msnm), el Peñón del Marqués (ó Peñón Viejo, $2372 \mathrm{msnm}$ ) y los flancos NE de la Sierra de Santa Catarina $(2750 \mathrm{msnm})$; dichos promontorios dividían el antiguo lago de Texcoco del Lago de Xochimilco.

Como rasgos hidrográficos se ubican el Río Churubusco, el Canal de Garay y el Canal de Chalco-Canal Nacional (actualmente todos entubados), los cuales conducen escurrimientos pluviales y de drenaje. Asimismo, los hundimientos del terreno que se registran en la zona generan daños a la infraestructura civil e hidráulica que produce continuas inundaciones cuya solución, hasta ahora, ha sido la canalización del agua de escorrentía a los drenes mencionados.

\section{Marco hidrogeológico}

El territorio de la delegación Iztapalapa está morfológicamente compuesto por una planicie constituida por depósitos arcillosos lacustres que integran un acuitardo que sobreyace a los materiales acuíferos de extensión regional, limitado por una serie de elevaciones topográficas de diferente altitud que representan una zona de recarga potencial al acuífero, al estar formados de materiales volcánicos de buena a alta permeabilidad. La mayor parte de la población de la delegación Iztapalapa se asienta sobre los depósitos lacustres.

En la parte más somera, los depósitos lacustres tienen 


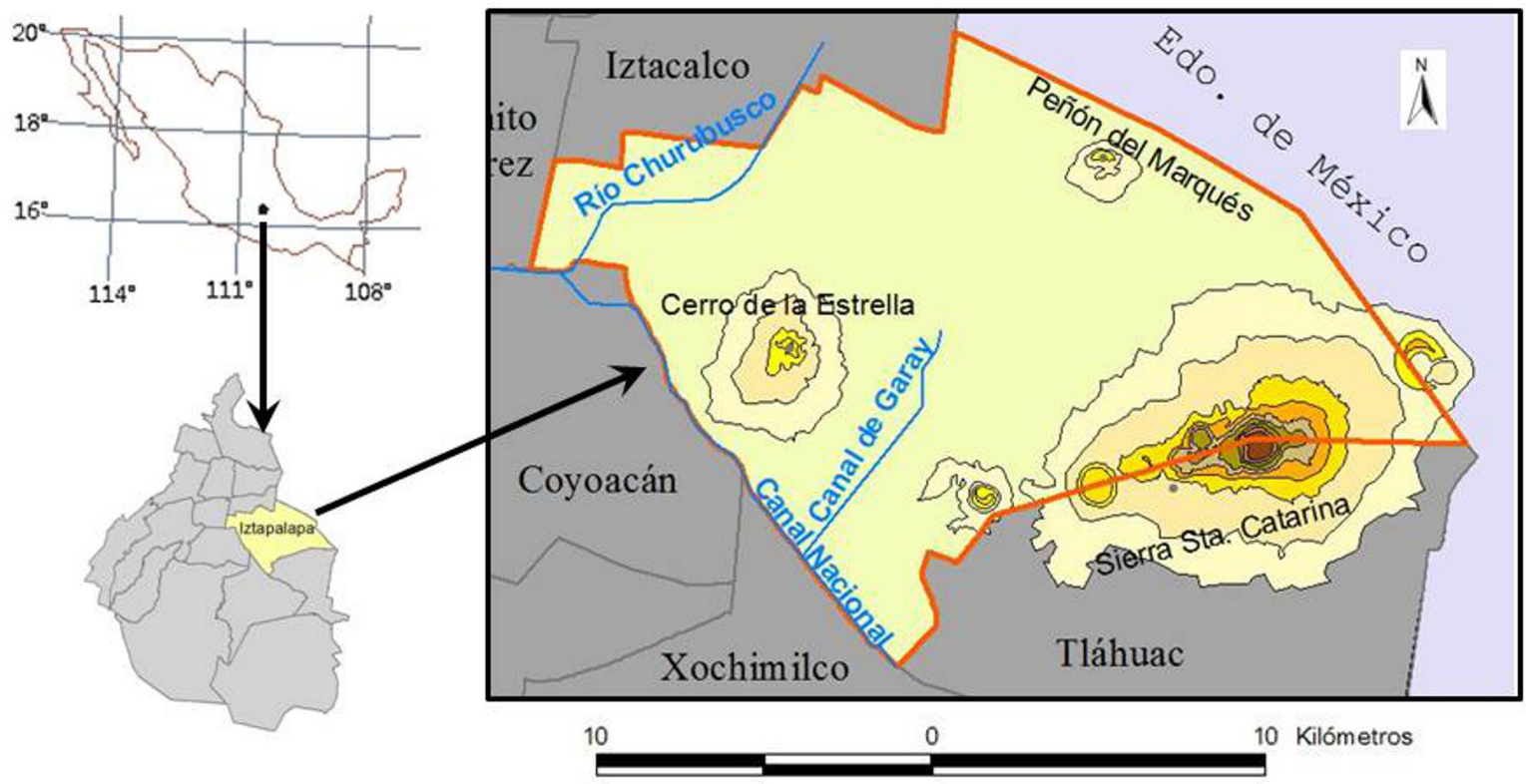

Figura 1. Localización de la delegación Iztapalapa con respecto al Distrito Federal y a la República Mexicana. Se observan los principales rasgos topográficos e hidrológicos (ya entubados), así como los nombres de las delegaciones políticas vecinas y el límite con el Estado de México

espesores que varían de 30 a $60 \mathrm{~m}$ dando confinamiento al acuífero subyacente en su parte superior (Vargas-Cabrera, 2001). Además de su composición limo-arcillosa, los depósitos lacustres finos se encuentran interestratificados con arenas piroclásticas que son conocidas en el ámbito geotécnico local como "capas duras" y son los horizontes donde se asientan las cimentaciones de las principales edificaciones de la ciudad.

La composición mineralógica del acuitardo tal como lo menciona Díaz-Rodríguez (2006) es única, ya que le confiere propiedades de alta compresibilidad y comportamiento tipo elástico (Díaz-Rodríguez et al., 1992); al superarse dicho esfuerzo, muestra excesiva deformación y cambios de volumen con predominante consolidación secundaria. El contenido de agua es de aproximadamente $220 \%$ a $30 \mathrm{~m}$ de profundidad y alcanza un máximo de $420 \%$ a $7 \mathrm{~m}$. El contenido mineralógico, de acuerdo a los mismos autores, se puede dividir en tres componentes principales.

- Componente alóctona, consiste en minerales detríticos como plagioclasa, hornblenda, hiperstena, cristobalita, vidrio volcánico, minerales arcillosos, ceniza volcánica y materia orgánica.

- Componente autóctona, precipitado de calcita bioquímica (valvas de ostrácodos y conchas de diatomeas, gasterópodos), sílice biogénica (frústulas de diatomeas), oolitos y abundante materia orgánica.

- Componente diagenética formada a partir de vidrio volcánico y minerales primarios alterados (sílice, ópalo y minerales ferromagnesianos). Se identificaron ópalo-CT (cristobalita-tridimita), cristobalita, goethita, calcita y pirita.

Lo anterior es producto de la biodiversidad existente en los lagos, la actividad volcánica circundante y con altas tasas de evaporación demostradas por Domínguez-Mariani, 1996). El acuífero que subyace al acuitardo lacustre está caracterizado por una intercalación de rocas ígneas cristalinas con piroclastos de composición basáltica, producto de la actividad volcánica durante el Cuaternario. Estos materiales volcánicos tienen alta permeabilidad primaria debido a que predominan derrames lávicos fracturados y autobrechados, además de que contienen vesículas interconectadas y forman localmente cavernas volcánicas (Vázquez-Sánchez, 1995). Los piroclastos intercalados con los derrames lávicos son materiales granulares cuyo tamaño de partícula va desde ceniza y lapilli hasta bloques volcánicos; por estas características, el acuífero presenta doble porosidad. La naturaleza litológica de los materiales define dos unidades acuíferas, la unidad acuífera volcánica granular y la unidad acuífera volcánica fracturada. Hacia la base de las unidades acuíferas se encuentran depósitos de lavas poco fracturadas $\mathrm{y}$ de materiales de grano fino que componen un acuitardo de poco espesor, conocido como acuitardo intermedio que forma el confinamiento inferior del acuífero descrito.

\section{Explotación intensiva}

De acuerdo a la configuración de la antigua zona lacustre de la Cuenca de México, la alimentación hidrológica provenía de las zonas montañosas hacia los lagos, vía escurrimiento superficial y también subterráneo. Sin embargo, tras la desecación de los lagos para el asentamiento de la Ciudad de México, sucedió su enorme expansión prácticamente a toda la cuenca, lo que generó cambios no sólo en los volúmenes de escurrimiento sino también en el almacenamiento subterráneo. 
La Figura 2 muestra las cargas hidráulicas (h) registradas en el año 2011 en pozos del Sistema de Aguas de la Ciudad de México (SACM, 2009). Se observa que en la planicie de la delegación convergen las cargas que provienen de la Sierra de Santa Catarina $\mathrm{h}=2175 \mathrm{msnm}$. Desde el sur se tiene un aporte de agua $(\mathrm{h}=2185) \mathrm{msnm}$ que arriban a la planicie. Se infiere que esta entrada es aprovechada mediante los pozos de extracción de la delegación. También existe una aportación horizontal desde el Peñón del Marqués y del noroeste, de la delegación Iztacalco (h $=2195 \mathrm{msnm}$ ). Las diversas componentes tienen origen en medios geológicos diferentes; por un lado la Sierra de Santa Catarina y el Peñón del Marqués están constituidos por rocas volcánicas principalmente piroclastos. En tanto que el flujo subterráneo procedente de Xochimilco y de Iztacalco proviene del acuífero regional. De tal manera que, en la planicie de la delegación se tiene actualmente la confluencia de flujo subterráneo de zonas circundantes. No se tienen suficientes información de cargas hidráulicas históricas de pozos de la delegación para establecer la existencia de zonas de abatimiento dentro de la delegación.

Una expresión de la extracción de agua subterránea que se ha realizado en la demarcación, es el abatimiento del nivel piezométrico puntual en los pozos. El máximo intervalo se alcanza en la cercanía del Cerro de la Estrella con 50 - 62.5 $\mathrm{m}$ en el periodo $1968-2010$, con descensos anuales de 1.2 a $1.6 \mathrm{~m}$. En el límite con la delegación Coyoacán se tienen descensos medios de $1.1 \mathrm{~m}$ y los menores cerca de la Sierra de Santa Catarina (33.2 m) con promedio anual de $0.8 \mathrm{~m}$, para el mismo periodo.

\section{Fracturamiento del terreno}

Los depósitos lacustres que sobreyacen al acuífero regional han experimentado compactación desde finales del siglo XIX (Carrillo, 1947), manifestándose en la superficie con hundimientos y fracturas del terreno, con efectos sobre la zona urbana como el rompimiento de las redes de distribución, así como de estructuras civiles. La teoría de la consolidación muestra que estos hundimientos se deben a la extracción generalizada de agua subterránea del acuífero bajo los depósitos lacustres (Carrillo, 1947; Terzaghi, 1925).

Vargas-Cabrera $(1995,2001)$ y Vargas-Cabrera y OrtegaGuerrero (2004) definen el comportamiento hidráulico de los sedimentos lacustres, conocidos como "arcillas de la

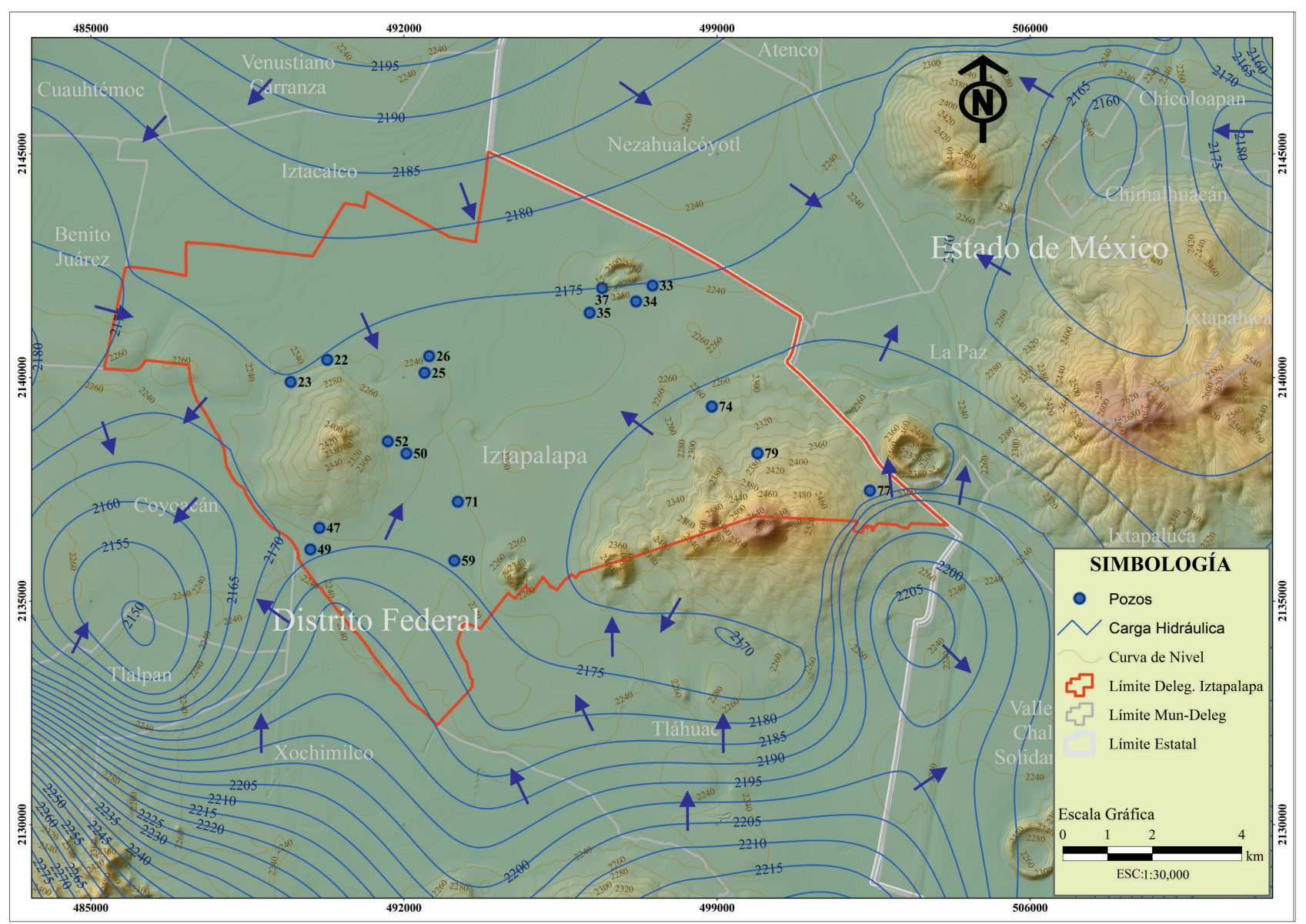

Figura 2. Ubicación de los pozos de la delegación Iztapalapa de los que se colectaron muestras de agua. Se observan las cargas hidráulicas (msnm) en la delegación Iztapalapa para el año 2011, de acuerdo a datos inéditos del SACM. 
Cd. de México", y el riesgo al que se encuentra sometida el agua en el acuífero subyacente en función de elevados valores de la conductividad hidráulica en superficie, aunado a la existencia de bajos valores del gradiente hidráulico; evidenciando una zona activa de flujo asociada a la presencia de fracturas en los primeros $10 \mathrm{~m}$ de profundidad en los bordes de la planicie y en los primeros $20 \mathrm{~m}$ en la parte central. Estos resultados tienen fuertes implicaciones sobre la vulnerabilidad a la contaminación del agua subterránea, una vez que las fracturas de la capa lacustre favorecen la migración de sustancias contaminantes desde la superficie del terreno hacia el acuífero del que se abastece la zona metropolitana.

El hundimiento de la Ciudad de México por la extracción de agua subterránea ha sido documentado por Jaramillo y Sánchez (2002) quienes muestran tasas de hundimiento que varían desde cero en Las Lomas, hasta casi $30 \mathrm{~cm} /$ año en el centro de la Ciudad de México. Por su parte, Cabral-Cano et al. (2002) reportan tasas de hundimiento en el oriente de la Cd. de México de $38.3 \mathrm{~cm} /$ año y en el centro de la Ciudad de México de $11.5 \mathrm{~cm} /$ año, durante el periodo de 1999 a 2000. Para la zona de Iztapalapa, la propia delegación ha documentado una amplia red de fracturas alrededor de la Sierra de Santa Catarina, Cerro de la Estrella y del Peñón del Marqués.

\section{Problemática en torno al agua en la delegación Iztapalapa}

El problema de abastecimiento de agua en la Ciudad de México es un caso tristemente conocido en el mundo, que se deriva del deterioro ambiental originado a partir del cambio de sus condiciones lacustres naturales hasta convertirse hoy en día en una de las ciudades más grandes del mundo. Izazola (2001) comenta que, a inicios del siglo XX, el suministro del agua a la Ciudad se componía de un $40 \%$ de agua subterránea proveniente de la propia cuenca y el $60 \%$ restante, de aguas superficiales propias. El SACM (2009) menciona que el abasto a la población del Distrito Federal se compone hoy en día de un $44.9 \%$ de agua subterránea y un $3.2 \%$ de agua superficial proveniente de la propia cuenca, además de un $12.3 \%$ de agua subterránea del Sistema Lerma y un $39.5 \%$ de agua aportada por el Sistema Cutzamala.

La delegación Iztapalapa es la demarcación más poblada de la Zona Metropolitana de la Ciudad de México (ZMCM), y para cubrir sus requerimientos hídricos también recurre a varias fuentes de abastecimiento externas debido a que las internas han disminuido. Tiene un suministro de agua subterránea proveniente de 78 pozos que aportan $1.3 \mathrm{~m}^{3} / \mathrm{s}$, más tres tanques de abastecimiento: Tanque la Caldera con un caudal que proviene del Sistema Cutzamala $\left(0.7 \mathrm{~m}^{3} / \mathrm{s}\right)$, Tanque Xaltepec $\left(0.6 \mathrm{~m}^{3} / \mathrm{s}\right)$ y Tanque Cerro de la Estrella $\left(1.8 \mathrm{~m}^{3} / \mathrm{s}\right)$ además del acueducto Santa Catarina $\left(0.7 \mathrm{~m}^{3} / \mathrm{s}\right)$, (DI, 2007). Como medidas de auxilio tiene el abastecimiento mediante pipas de agua potable (en promedio $3400 \mathrm{~m}^{3} / \mathrm{d}$ ), derivado de que el abasto se proporciona sólo algunas horas al día ("tandeo") en 68 colonias, es decir, en el $38 \%$ del área de la delegación, (DI, 2007).

A pesar del aporte de las diferentes fuentes, el abasto no es constante ni suficiente en la totalidad del territorio debido a la disminución de caudales disponibles, sobre todo al descenso de los niveles locales de bombeo y a la dependencia de la disponibilidad desde fuentes externas.

En cuanto a la composición hidrogeoquímica del agua subterránea de la Ciudad de México, Edmunds et al. (2002) definieron la participación de varios procesos como aportes de agua de lluvia, interacción agua-roca (de composición basáltica y/o riolítica), zonas con anomalías termales, zonas cercanas al límite redox, contaminación desde la superficie y la presencia del ión nitrato. Los primeros cuatro procesos se producen de manera natural en el sistema acuífero, en tanto que los últimos dos se presentan como intervención antropogénica de manera directa o bien, de manera indirecta, es decir, inducidos por el bombeo intensivo.

Huizar-Álvarez et al. (2004) encontraron evidencias de que la capacidad del acuitardo como sello había disminuido debido principalmente al descenso de la carga hidráulica en el acuífero, con lo cual se induciría la migración de agua con mayor contenido iónico desde el acuitardo hacia los pozos de extracción. Esto se debe a que, en condiciones originales en el acuitardo, las cargas hidráulicas se encontraban muy cerca del nivel del terreno; en esta situación, las fases mineralógicas se encontraban en equilibrio. Posteriormente, a causa del bombeo intensivo, el agua intraporo inició su paso mediante "goteo" hacia el acuífero regional con los diferentes minerales en solución (Rudolph et al., 1991; Domínguez-Mariani, 1996). De tal manera que, bastaba un $3 \%$ de agua del acuitardo para que al combinarse con $97 \%$ de agua del acuífero, para que el ión $\mathrm{Na}^{+}$superara el Límite Máximo Permisible (LMP) para agua potable establecido en la NOM-127-SSA1-1994 (Domínguez-Mariani, 1996).

En muestras de agua tomadas de piezómetros de profundidad de 7 a $40 \mathrm{~m}$ en el acuitardo, la conductividad eléctrica (CE) tenía el rango de 6390 a $19000 \mu \mathrm{S} / \mathrm{cm}$, en tanto que el contenido de $\mathrm{Cl}^{-}$era de $292-1900 \mathrm{mg} / \mathrm{L}$, (Domínguez-Mariani, 1996). Un aspecto importante era el contenido de $\mathrm{Fe}^{2+}$ y $\mathrm{Mn}^{2+}$ que se encontraba en el rango de $1.28-1.84 \mathrm{mg} / \mathrm{L}$ y $0.17-0.25 \mathrm{mg} / \mathrm{L}$ respectivamente con presencia de condiciones reductoras. La composición del agua subterránea a partir de dos pozos de la batería Santa Catarina ( $400 \mathrm{~m}$ de profundidad) mostraba que la CE tenía un intervalo de $1000-4020 \mu \mathrm{S} / \mathrm{cm}$ y el Cl- estaba entre de 25.5 - $12 \mathrm{mg} / \mathrm{L}$ (Domínguez-Mariani, 1996). En cuanto al contenido de $\mathrm{Fe}^{2+} \mathrm{y} \mathrm{Mn}^{2+}$, los intervalos eran de $0.09-0.14$ $\mathrm{mg} / \mathrm{L}$ y de $0.05-0.23 \mathrm{mg} / \mathrm{L}$ respectivamente.

La correlación positiva del ión nitrato y la demanda química de oxígeno (DQO) a partir de datos de SACM (2009) para agua extraída de pozos de la demarcación, podría asociarse a la influencia de agua residual infiltrada por fracturas en el acuitardo, pero también a la materia orgánica señalada por Díaz-Rodríguez et al. (1992). De tal 
manera que pozos ubicados al NW del Cerro de la Estrella, poniente de la Sierra de Santa Catarina y algunos en el centro del valle tuvieron los mayores valores de DQO. Lo anterior evidencia la oxidación de materia orgánica de manera continua en el acuitardo, lo que provoca a su vez el desarrollo de condiciones reductoras.

En cuanto a los iones $\mathrm{Cl}^{-}$y $\mathrm{Na}^{+}(\mathrm{mg} / \mathrm{L})$, el ión $\mathrm{Cl}^{-}$en el agua subterránea estaba en el rango de 34.1 a 394.6 $\mathrm{mg} / \mathrm{L}$ y el ión $\mathrm{Na}^{+}$entre 54 a $1008 \mathrm{mg} / \mathrm{L}$, siendo los pozos ubicados entre la Sierra de Santa Catarina y el Cerro de la Estrella, los que tenían los valores máximos de acuerdo con datos de SACM (2009). La presencia de salinidad en agua subterránea significaría el aporte de agua evaporada del agua del acuitardo, Domínguez-Mariani (1996). De acuerdo a la NOM-127-SSA1-1994 (DOF, 2000) para el ión $\mathrm{Cl}^{-}$, el valor normativo es de $250 \mathrm{mg} / \mathrm{L}$ y para el ión $\mathrm{Na}^{+}$de $200 \mathrm{mg} / \mathrm{L}$, valores que eran superados en una gran mayoría de los pozos.

Las concentraciones de Fe y Mn determinadas en el agua subterránea en 2009 tuvieron como intervalos 0.05 $3.57 \mathrm{mg} / \mathrm{L}$ y $0.019-3.32 \mathrm{mg} / \mathrm{L}$, respectivamente. La NOM 127-SSA1-1994 (DOF, 2000) marca el valor de $0.3 \mathrm{mg} / \mathrm{L}$ para $\mathrm{Fe}^{2+}$ y de $0.15 \mathrm{mg} / \mathrm{L}$ para $\mathrm{Mn}^{2+}$. De tal manera que $7 \mathrm{de}$ 18 pozos extraían en 2009 agua fuera de norma para $\mathrm{Fe}^{2+}$ y 8 pozos de los 18 muestreados para $\mathrm{Mn}^{2+}$. Los valores más altos se ubicaban al poniente del Cerro de la Estrella. Es importante señalar que las concentraciones reportadas para el agua subterránea para 2009, fecha de este estudio, se aproximan a las referidas para el acuitardo por DomínguezMariani (1996).

De acuerdo con lo anterior, la calidad del agua subterránea de la delegación Iztapalapa se ha venido deteriorando, ubicándose fuera de los estándares marcados por la NOM-127-SSA1-1994. Los problemas que se tienen con la extracción creciente, son continuos descensos del nivel más allá del nivel de bombeo e incremento de la mala calidad del agua subterránea, que ocasionan que cuando el agua de un pozo en particular no es recomendable para el abastecimiento, el SACM clausura el pozo. Este proceso se ha vuelto continuo en la delegación, lo que representa una significativa reducción de los volúmenes de agua dentro de los estándares recomendados para el suministro a la población. Por lo anterior, se han instalado sistemas de tratamiento del agua en cada pozo, cuyo número es creciente y ocasiones insuficiente para llegar a los LMP para agua potable.

\section{Metodología}

Se seleccionaron un total de 17 pozos de abastecimiento público en operación, distribuidos en la delegación Iztapalapa a cargo del SACM (Figura 2), con el fin de colectar muestras de agua y conocer la composición química en cuanto a iones mayores y traza. El muestreo se realizó en julio de 2012 en cada uno de los pozos, tanto antes como después del sistema de tratamiento instalado. En el presente artículo se muestra el análisis de la composición del agua antes del tratamiento que se efectúa en cada pozo. El material utilizado en el muestreo fue previamente lavado en el laboratorio siguiendo las recomendaciones de la APHA-AWWA y WPCF (1992), donde también se realizó la calibración de los equipos de medición que se utilizaron en campo. Para la medición de $\mathrm{pH}, \mathrm{CE}$ y temperatura se utilizó un medidor multiparamétrico Hanna Instruments 9812, el $\mathrm{pH}$ que fue calibrado con tres soluciones buffer (4, 7 y 10). Para la calibración de CE se utilizó una solución estándar HI7031L de $1413 \mu \mathrm{S} / \mathrm{cm}$. La determinación de la alcalinidad total y fenolftaleína se realizó por el método de titulación con bureta utilizando soluciones normalizadas de $\mathrm{HCl}$ de 0.01 N (Cat. 5611-02 de J.T.Baker) y 0.1 N (Cat. 5621-02 de J.T.Baker). El indicador utilizado fue anaranjado de metilo.

El análisis de cationes se realizó con un espectrómetro de emisión óptica con plasma acoplado por inducción Thermo iCAP 6500 Duo View y los aniones, con un cromatógrafo de líquidos de alta resolución Dionex ICS-2500 HPLC/ IC con bomba de gradiente cuaternario y detectores de conductividad del Laboratorio de Geoquímica Ambiental del Centro de Geociencias de la UNAM. La turbidez se analizó con un turbidímetro Hach2100AN3. La DQO se llevó a cabo mediante el método de digestión de reactor DR/2010 de Hach. Se realizó la determinación de coliformes fecales por el método de NMP (Número Más Probable), estas determinaciones fueron realizadas en el Laboratorio de Aguas Residuales de la UAM Unidad Iztapalapa.

Las muestras colectadas para cationes fueron acidificadas hasta $\mathrm{pH}<2$ con $\mathrm{HNO}_{3}$ Ultrex a fin de estabilizar los metales y evitar que la precipitación disminuya la concentración original. Las muestras para aniones y cationes fueron filtradas con una membrana de poro $0.45 \mu \mathrm{m}$ de marca Millipore.

Se tomaron muestras de agua para el análisis de isótopos estables realizados por Isotech Labs. Para el análisis en muestras de agua de $\delta^{18} \mathrm{O}$ se utilizó una modificación del método del equilibrio del $\mathrm{CO}_{2}$ del agua originalmente descrita por Epstein y Mayeda (1953). Para el análisis de $\delta \mathrm{D}$ se utilizó el método de reducción de $\mathrm{Zn}$ originalmente descrito por Coleman et al. (1982) y Vennemann y O’Neil (1993) con las modificaciones descritas por Hackley et al. (1999).

Para el caso de las muestras para turbidez y DQO los tiempos entre la toma de muestra y el traslado a los laboratorios de destino fueron de máximo 2 horas. El balance iónico tuvo valores máximos $15 \%$. Se realizó la determinación del índice de saturación (IS) mediante el software PHREEQC versión 3 (USGS, 2014), donde se utilizaron datos medidos en campo (temperatura, $\mathrm{pH}$, alcalinidad), iones mayores $\left(\mathrm{Na}^{+}, \mathrm{Cl}^{-}, \mathrm{K}^{+}, \mathrm{Si}^{4+} \mathrm{Mg}^{2+}, \mathrm{Ca}^{2+}\right.$ ) y menores $\left(\mathrm{F}^{-}, \mathrm{Li}^{+}, \mathrm{P}^{5+}, \mathrm{SO}_{4}^{2-}, \mathrm{Fe}^{2+}, \mathrm{Mn}^{2+}, \mathrm{Pb}^{2+}, \mathrm{Sr}^{+}\right)$. 


\section{Análisis y discusión de resultados}

\subsection{Iones mayores}

Las diversas componentes de flujo subterráneo que arriban a la zona de descarga, como se considera actualmente a la planicie de la delegación Iztapalapa, se ven reflejadas en la composición fisicoquímica del agua subterránea. La relación $\mathrm{Cl}^{-} v s$. CE muestra que los valores más bajos corresponden al agua subterránea colectada en el Peñón del Marqués, compuesto de piroclastos. A continuación se ubica la entrada horizontal procedente de Xochimilco que tiene influencia tanto de agua de poro del acuitardo lacustre y también de la recarga de la Sierra de Chichinautzin (Montiel-Palma et al., 2014) (Figura 3). Los valores más altos de estos dos parámetros proceden de la Sierra de Santa Catarina que se asocia a la infiltración intencional de agua residual vía fracturas. Otro componente de carácter regional es la entrada horizontal procedente de Iztacalco, que de acuerdo al contenido de $\mathrm{Cl}^{-}$y $\mathrm{CE}$, tiene influencia de agua del acuitardo; esta componente se ubica a continuación de la correspondiente a Santa Catarina. La mezcla final de los diversos componentes, se refleja en la composición del agua subterránea extraída en la planicie, representada por los puntos medios de la gráfica. Localmente, se estima que el flujo descendente desde el acuitardo participa como una componente adicional en la composición fisicoquímica, debido a fracturamiento local o bien, a flujo inducido mediante bombeo intensivo.

Una característica del agua subterránea de la delegación Iztapalapa es el sabor salino, que se infiere está asociado con los iones $\mathrm{Na}^{+}(91.4-598.1 \mathrm{mg} / \mathrm{L})$ y Cl$(59.4-372.3$ $\mathrm{mg} / \mathrm{L}$ ), los cuales superan las concentraciones límite que marca la NOM-127-SSA1-1994 (200 mg/L para $\mathrm{Na}^{+}$y 250 $\mathrm{mg} / \mathrm{L}$ para $\mathrm{Cl}^{-}$). Para $\mathrm{Na}^{+}, 10$ de los 17 pozos muestreados



Figura 3. Concentraciones de $\mathrm{Cl}^{-}(\mathrm{mg} / \mathrm{L})$ y C.E. $(\mu \mathrm{S} / \mathrm{cm})$ en agua subterránea colectada de pozos de la delegación Iztapalapa. Se muestran las zonas en que se ha divido a la delegación: zona NW, Peñón del Marqués, pozos próximos a Xochimilco, Planicie de la delegación y la Sierra de Santa Catarina, así como la característica principal en la composición del agua. superan la norma mexicana para agua potable (DOF, 2000) y en el caso del ion $\mathrm{Cl}^{-}$ocurre en 7 de los 17.

El diagrama de Piper (Figura 4) confirma que los cationes que predominan en el agua subterránea de la zona de estudio son el $\mathrm{Na}^{++} \mathrm{K}^{+}$(Figura 4), cuyo origen es el aporte de agua evaporada es decir, del agua de poro del acuitardo (Domínguez-Mariani, 1996). El paso progresivo que ha tenido hacia el acuífero principal se refleja en la mezcla con agua originalmente mixta, como aún se observa en los puntos 47 y $49(20 \% \mathrm{Ca}, 20 \% \mathrm{Mg}$ y $60 \% \mathrm{Na}^{++} \mathrm{K}^{+}$) procedentes de Xochimilco. Así mismo, la interacción con rocas volcánicas ácidas a intermedias también otorga el dominio de estos iones, como es el caso de agua colectada en Peñón del Marqués. Un caso especial son las muestras colectadas en la Sierra de Santa Catarina con $\mathrm{Na}^{++} \mathrm{K}^{+}$dominante $(95 \%)$ lo que se asocia con agua residual. La mezcla entre estas componentes determina la composición del agua en los puntos 22, 23, 25 y 26 y en la planicie (pozos 50, 59, 52 y 71). Otra razón de que el Ca se encuentre disminuido en todas las muestras, es participa en la precipitación de calcita, determinada mediante el uso del software PHREEQC.

En cuanto a los aniones, el $\mathrm{HCO}_{3}^{-}$es el ión predominante con dos probables orígenes: agua de precipitación pluvial, ó bien, agua del acuitardo. En el Peñón del Marqués se ubica por debajo del $80 \%$; el origen de este ión podría proceder del agua de lluvia ó a la influencia del agua del acuitardo que también lo contiene, lo anterior significaría que los procesos de recarga aún son activos debido a una fuerte presencia de rocas volcánicas. En las muestras ubicadas al SW de la delegación (pozos 47 y 49), el ión $\mathrm{SO}_{4}{ }^{2-}$ es abundante y se asocia con mayor presencia de agua evaporada procedente del acuitardo. El agua colectada en Santa Catarina muestra una composición mixta en cuanto a aniones como mezcla del agua subterránea local con agua residual. La composición del agua de la planicie y de los pozos 22, 23, 25 y 26 tienen un predominio del ión $\mathrm{HCO}_{3}^{-}$, en este caso se supone la influencia del agua del acuitardo. Para estos puntos, las concentraciones de $\mathrm{SO}_{4}^{2-}$ son muy bajas mostrando incluso condiciones de reducción del ión sulfato como lo reporta Edmunds et al. (2002).

El diamante central del diagrama de Piper muestra que la composición del agua subterránea del Peñón del Marqués es bicarbonatada-sódico-potásica, los puntos correspondientes se ubican muy cercanos entre sí, aparentemente preservando su composición original. En tanto que los pozos 22, 23, 25 y 29 (Iztacalco) muestran el agua con la mayor proporción de agua del acuitardo, que mediante flujo horizontal tiene cierta dilución con la componente de Xochimilco (47 y 49), dando como resultado que la composición del agua de la planicie muestre diferentes proporciones entre los iones, debido a la influencia de flujo regional de los alrededores y de un componente vertical descendente desde el acuitardo.

El diagrama de Stiff para la zona (Figura 5), muestra que la familia que se presenta en la mayoría de los puntos muestreados es $\mathrm{Na}^{+}+\mathrm{K}^{+}>\mathrm{Ca}^{2+}>\mathrm{Mg}^{2+}$ y $\mathrm{HCO}_{3}^{-}>\mathrm{Cl}^{-}>$ 


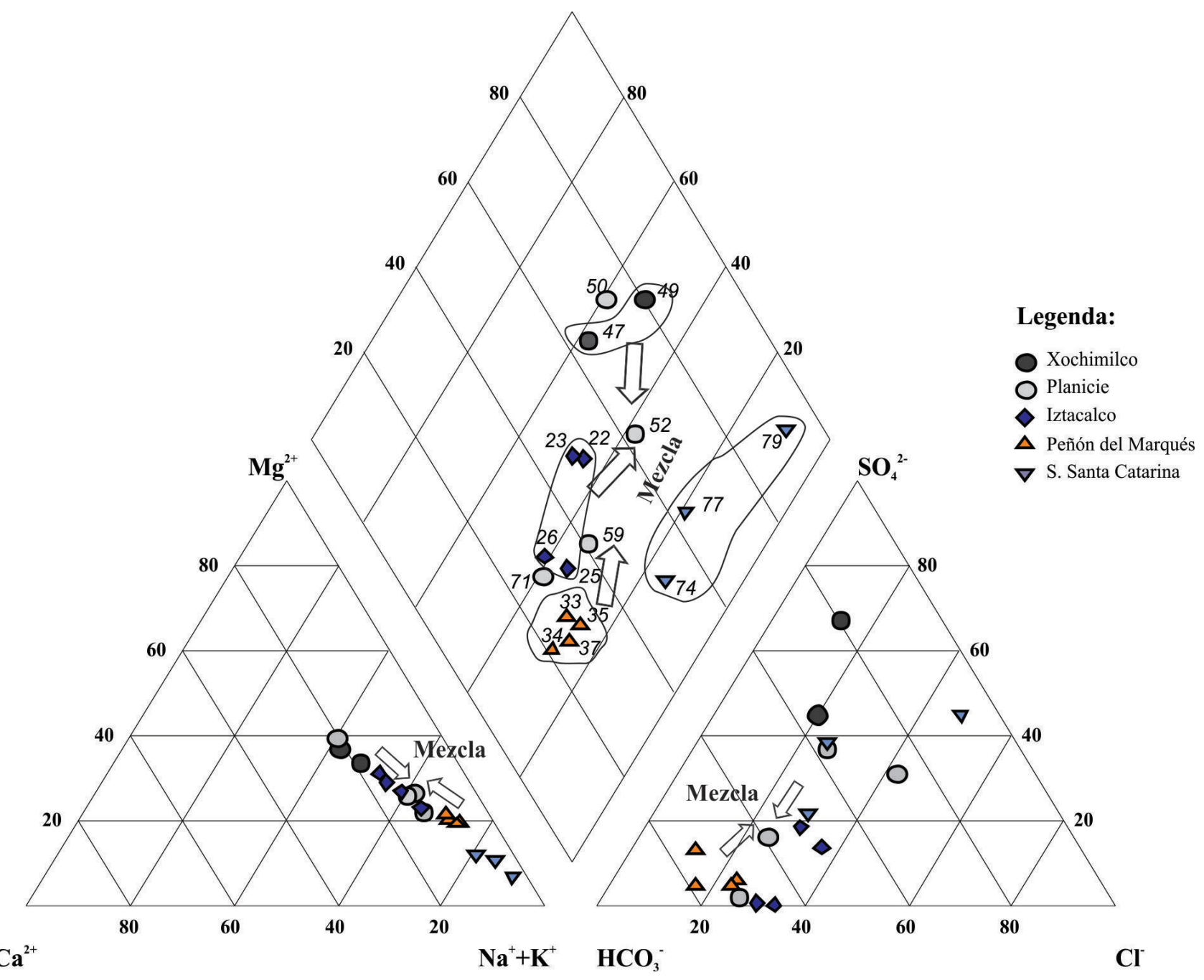

Figura 4. Diagrama de Piper realizado a partir de las concentraciones iónicas determinadas en el agua subterránea de la delegación Iztapalapa. Se muestran las componentes de flujo subterráneo identificadas (zona NW, Peñón del Marqués, pozos próximos a Xochimilco, Planicie de la delegación y en la Sierra de Santa Catarina) y los procesos de mezcla entre estas.

$\mathrm{SO}_{4}^{2-;}$ los puntos con contenido iónico más alto se ubican en los pozos 22, 26, 25, 26 y 74; con la misma relación entre iones pero menor contenido iónico se ubican en el Peñón del Marqués y en la planicie (59 y 71). Al SW, los pozos $43,49,50$ y 52 muestran menor contenido iónico con la particularidad de que el ión $\mathrm{HCO}_{3}^{-}$no es el ión dominante. En la Sierra de Santa Catarina los pozos 77 y 79 tienen elevada concentración de los iones, con la relación $\mathrm{Na}^{+}+\mathrm{K}^{+}$ $>\mathrm{Ca}^{2+}>\mathrm{Mg}^{2+}$ y SO $_{4}{ }^{2-} \sim \mathrm{Cl}^{-}>\mathrm{HCO}_{3}{ }^{-}$, asociada a infiltración de agua residual.

Un factor determinante en la composición del agua de la delegación es el contenido de $\mathrm{Fe}^{2+} \mathrm{y} \mathrm{Mn}^{2+}$ que en algunos casos rebasan los límites establecidos para la NOM-127-SSA1-1994 (DOF, 2000). El contenido de $\mathrm{Fe}^{2+}$ supera el valor normativo de $0.3 \mathrm{mg} / \mathrm{L}$ en tres de los pozos muestreados, mientras que, en el caso del valor máximo permisible para $\mathrm{Mn}^{2+}(0.15 \mathrm{mg} / \mathrm{L})$ se tienen 8 pozos fuera de la norma referida (Figura 6). En la citada figura, se distinguen cuatro comportamientos:

1. Concentraciones bajas de iones de $\mathrm{Fe}^{2+}$ y $\mathrm{Mn}^{2+}$ en Xochimilco y Peñón del Marqués.

2. Valores elevados de $\mathrm{Mn}^{2+}$ y bajos de $\mathrm{Fe}^{2+}$ en los pozos 22 y 23, ubicados al norte del Cerro de la Estrella probablemente asociados al agua de poro del acuitardo.

3. Valores altos de $\mathrm{Fe}^{2+}$ y bajos de $\mathrm{Mn}^{2+}$ en los pozos localizados en la Sierra de Santa Catarina que se asocian a fuentes antropogénicas desde superficie (Herndon et al., 2011) o a la oxidación de efluentes domésticos que contienen materia orgánica (Goren, 2009).

4. Valores altos en ambos parámetros, que ocurre en pozos ubicados en la planicie y en los pozos 25 y 29 , lo que significa el efecto combinado de ambos procesos, tanto aportación del acuitardo como de fuentes antropogénicas.

De acuerdo con Domínguez-Mariani (1996) el contenido 




Figura 5. Diagramas de Stiff realizado a partir de las concentraciones iónicas determinadas en el agua subterránea de pozos de la delegación Iztapalapa, que permitieron definir cuatro diferentes familias: $\mathrm{HCO}_{3}^{-}-\mathrm{Na}^{+}+\mathrm{K}^{+}$(naranja), $\mathrm{SO}_{4}{ }^{2-}-\mathrm{HCO}_{3}^{-}-\mathrm{Na}^{+}$(guinda); $\mathrm{Cl}^{-}-\mathrm{SO}_{4}^{2-}-\mathrm{Na}^{+}+\mathrm{K}^{+}-\mathrm{Cl}^{-}\left(\right.$morado); $\mathrm{SO}_{4}^{2-}-\mathrm{Na}^{+}+\mathrm{K}^{+}-\mathrm{Cl}^{-}($azul) ).

de $\mathrm{Fe}^{2+} \mathrm{y} \mathrm{Mn}^{2+}$ en muestras de agua subterránea colectada en pozos de la Batería de Santa Catarina, estaba en el intervalo de $0.09-0.14 \mathrm{mg} / \mathrm{L}$ y $0.05-0.23 \mathrm{mg} / \mathrm{L}$, mientras que para el presente, los intervalos para estos iones en Iztapalapa son de $(0.004-0.64 \mathrm{mg} / \mathrm{L}$ y $0.003-0.96 \mathrm{mg} / \mathrm{L})$. De tal manera que se ha incrementado el contenido de ambos iones en agua del acuífero. El contenido de $\mathrm{Fe}^{2+}$ y $\mathrm{Mn}^{2+}$ en agua de poro del acuitardo era de $1.28-1.84 \mathrm{mg} / \mathrm{L}$ y $0.17-0.25 \mathrm{mg} / \mathrm{L}$, respectivamente; los valores determinados para el agua subterránea son aún menores en el caso del $\mathrm{Fe}^{2+}$ y mayores en el caso del $\mathrm{Mn}^{2+}$. Existe una tendencia a precipitar minerales que contienen $\mathrm{Fe}^{2+}$ y $\mathrm{Mn}^{2+}$, de acuerdo al cálculo de los índices de saturación, lo que se observa en las redes de agua de abastecimiento que tienen un revestimiento interior por esta causa.

Las características organolépticas del agua extraída de los pozos son fuerte aroma (que varía de inapreciable a azufre o a "huevo podrido"), color (comúnmente referido como amarillo-café) y apariencia turbia. Lo anterior, es causa de insatisfacción para los consumidores y proporciona a las autoridades elementos de primera mano para calificar, de manera rápida, la calidad del agua que se extrae de los pozos de la delegación, como apta o no para el consumo

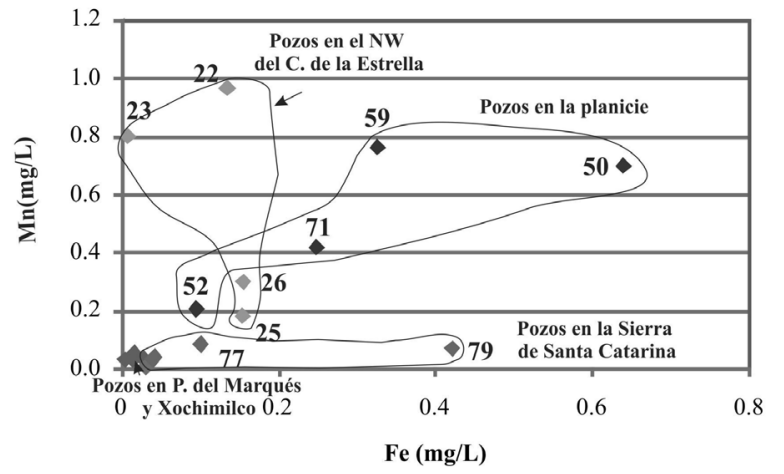

Figura 6. Concentraciones de $\mathrm{Fe}^{2+}$ y $\mathrm{Mn}^{2+}(\mathrm{mg} / \mathrm{L})$ de agua subterránea extraída de pozos de la delegación Iztapalapa. Se muestran las zonas en que se ha agrupado la delegación: zona NW, Peñón del Marqués, pozos próximos a Xochimilco, Planicie de la delegación y Sierra de Santa Catarina.

humano. Los aromas percibidos son muestra de condiciones reductoras asociadas a $\mathrm{H}_{2} \mathrm{~S}$ producido por la reducción de $\mathrm{SO}_{4}^{2-}$ a S- mediante bacterias sulfato reductoras en ambientes deficientes en oxígeno y de depósitos de materia orgánica en descomposición (Varner et al., 1996). La presencia de 
este aroma permitió identificar en campo, condiciones de reducción de ión sulfato.

La presencia de turbidez en el agua subterránea tiene valores cercanos a 0.5 hasta 4.37 NTU (Nephelometric Turbidity Units) que corresponden también a las mayores concentraciones de Fe y Mn de pozos ubicados al norte del Cerro de la Estrella, en la planicie y en la Sierra de Santa Catarina (Tabla 1), esto se explica mediante la formación de partículas suspendidas en forma de complejos a partir de las elevadas concentraciones de los iones.

La determinación de DQO permitió evaluar el contenido de la materia orgánica susceptible de ser oxidada, considerando que podría será portada por agua residual. Los valores obtenidos fueron de $3.75-63.75$ $\mathrm{mg} / \mathrm{L}$, lo que significaría que el agua es de buena calidad a contaminada de acuerdo con la Comisión Nacional de Agua (CNA, 2015). Los valores mayores se ubican en la Sierra de Santa Catarina, descendiendo están los ubicados en la planicie de Iztapalapa, luego los localizados cerca de Xochimilco, después Peñón del Marqués y finalmente los ubicados al NW de Iztapalapa (Figura 7). Pese a que los pozos que proporcionan agua de mala calidad se clausuran, se tiene el registro de que el pozo 34 tenía $10 \mathrm{mg} / \mathrm{L}$ de DQO en 2008 y actualmente $52.5 \mathrm{mg} / \mathrm{L}$ y, que el pozo 35 tenía $10 \mathrm{mg} / \mathrm{L}$ en 2008 y $48.75 \mathrm{mg} / \mathrm{L}$ en 2012. El origen de los valores medidos de DQO podría ser la materia orgánica proveniente desde el acuitardo (Díaz-Rodríguez, 2006), o bien, la aportada por infiltración de agua residual desde la superficie, favorecida por las fracturas en material volcánico en la Sierra de Santa Catarina o en el acuitardo en la planicie de Iztapalapa.

\section{2 Índices de saturación}

Los minerales que causan turbidez y provocan los depósitos de color café claro a negro en la red de agua potable fueron determinados mediante el cálculo de los índices saturación con el software PHREEQC v3.12. Durante el proceso de filtración de las muestras de agua en el campo que se llevaron a laboratorio, se observó material retenido en las membranas de celulosa que sirvieron de filtro, por lo que las cantidades de las fases determinadas mediante la modelación deberán estar en mayor concentración. Como una primera aproximación a las condiciones reductoras del subsuelo, se incluyeron valores de $\mathrm{pe}=-4$ (pe $=$ potencial electrón) en todos los pozos, debido a que de acuerdo con las observaciones de campo, presentaron de aroma fétido medio a intenso, con los cuales se obtuvieron valores de presión para gases como $\mathrm{H}_{2} \mathrm{~S}$ y $\mathrm{CH}_{4}$ mayor a $10 \times 10^{-10} \mathrm{~atm}$ en los pozos $26,49,52,59$ y 7 localizados en la planicie y en el pozo 35 en Peñón del Marqués (Tabla 2).

La Tabla 2 muestra los índices de saturación de óxidos e hidróxidos de $\mathrm{Fe}^{2+}$, carbonatos, fosfatos, silicatos, así como algunos gases. En general los carbonatos y barita $\left(\mathrm{BaSO}_{4}\right)$ se encuentran cercanos al equilibrio. Las fases de sílice se encuentran en el equilibrio a ligeramente sobresaturados. En cambio, minerales con presencia de Fe muestran una tendencia a estar sobresaturados.

En la Figura 8 se muestran los índices de saturación obtenidos para el agua subterránea de pozos característicos de cada una de las zonas en que se ha dividido el área de estudio. Los mayores índices de saturación son para óxidos de Fe, especialmente magnetita y hematita, cuyos mayores índices corresponden al pozo 47 cercano a Xochimilco, a

Tabla 1. Resultados de los análisis químicos de muestras de agua tomadas de pozos a cargo del SACM. de acuerdo a datos inéditos del SACM.

\begin{tabular}{|c|c|c|c|c|c|c|c|c|c|c|c|c|c|c|c|}
\hline No. & Nombre & $\begin{array}{l}\mathrm{Ca}^{2+} \\
\mathrm{ppm}\end{array}$ & $\begin{array}{l}\mathrm{Fe}^{2+} \\
\mathrm{ppm}\end{array}$ & $\begin{array}{c}\mathbf{K}^{+} \\
\mathrm{ppm}\end{array}$ & $\begin{array}{l}\mathbf{M g}^{2+} \\
\mathrm{ppm}\end{array}$ & $\begin{array}{l}\mathbf{M n}^{2+} \\
\mathrm{ppm}\end{array}$ & $\begin{array}{l}\mathbf{N a}^{+} \\
\mathrm{ppm}\end{array}$ & $\begin{array}{l}\mathrm{Cl}^{-} \\
\mathrm{ppm}\end{array}$ & $\begin{array}{c}\mathbf{S O}_{4}{ }^{2-} \\
\mathrm{ppm}\end{array}$ & $\begin{array}{r}\mathrm{HCO}_{3}^{-} \\
\mathrm{mg} / \mathrm{L}\end{array}$ & $\begin{array}{l}\text { DQO } \\
\mathrm{mg} / \mathrm{L}\end{array}$ & $\begin{array}{c}\text { Turbidez } \\
\text { (NTU) }\end{array}$ & $\begin{array}{c}\delta \mathrm{D} \mathbf{H}_{2} \mathbf{O} \\
\% 0\end{array}$ & $\begin{array}{c}\delta^{18} \mathrm{O} \mathrm{H}_{2} \mathrm{O} \\
\%_{0}\end{array}$ & $\begin{array}{l}\mathbf{C E} \\
\mu \mathrm{S} / \mathrm{cm}\end{array}$ \\
\hline 22 & Iztapalapa 1 & 77.1 & 0.13 & 28.3 & 84.5 & 1 & 284.5 & 338.4 & 173 & 793 & 56.3 & 2.3 & -66.6 & -9.5 & 1990 \\
\hline 23 & Iztapalapa 2 & 63.1 & 0.01 & 19.6 & 71.9 & 0.8 & 217.9 & 224.2 & 186.3 & 660.8 & 28.8 & 0.9 & -68 & -9.7 & 1700 \\
\hline 25 & PT Purísima Iztapalapa 3 & 46.4 & 0.15 & 26.1 & 52.5 & 0.2 & 263.8 & 287.9 & 0.3 & 956.1 & 36.3 & 0.5 & -67.8 & -9.5 & 1930 \\
\hline 26 & Purísima Iztapalapa 7B & 67.8 & 0.15 & 26.5 & 76.9 & 0.3 & 303.5 & 366.4 & 9.5 & 1423.3 & 6.3 & 0.4 & -67.9 & -9.5 & 1700 \\
\hline 33 & Peñón 5 & 15.2 & 0.01 & 17.7 & 22.8 & 0.05 & 132.2 & 97.1 & 24.2 & 508.3 & 3.8 & 0.5 & -71.5 & -10 & 800 \\
\hline 34 & Peñón 6 & 11.9 & 0.004 & 18.1 & 16.7 & 0.03 & 101.5 & 62.8 & 24.1 & 508.3 & 52.5 & 0.4 & -74.2 & -10.1 & 620 \\
\hline 35 & Peñón 7 & 12.5 & 0.01 & 17.4 & 19.9 & 0.03 & 134.2 & 80.2 & 28 & 406.7 & 48.8 & 0.4 & -72.2 & -9.9 & 750 \\
\hline 37 & Peñón 9 & 10.9 & 0.03 & 18.1 & 19.6 & 0.03 & 127.4 & 59.4 & 85.4 & 610 & 16.3 & 0.1 & -72.2 & -10.2 & 710 \\
\hline 47 & Granjas Estrella 1 & 51.1 & 0.04 & 11.3 & 54.6 & 0.003 & 108.7 & 92.9 & 288.8 & 284.7 & 17.5 & 0.3 & -71.4 & -10.1 & 1150 \\
\hline 49 & Granjas Estrella 3 & 33.4 & 0.04 & 8.8 & 36.8 & 0.04 & 91.4 & 88.6 & 611.2 & 223.7 & 13.8 & 0.4 & -71.8 & -10.2 & 870 \\
\hline 50 & Panteón Civil 1 & 72.8 & 0.6 & 15.3 & 85.4 & 0.7 & 154.4 & 372.3 & 371.9 & 406.7 & 13.8 & 4.4 & -70.8 & -10 & 1630 \\
\hline 52 & Panteón Civil 3 & 46.8 & 0.1 & 20.7 & 61.5 & 0.2 & 255.7 & 179.9 & 349.9 & 447.3 & 18.8 & 0.4 & -70.5 & -9.8 & 1680 \\
\hline 59 & Santa Catarina 13 & 51.3 & 0.3 & 17.3 & 55 & 0.8 & 293.9 & 190.8 & 170.6 & 787.9 & 27.5 & 1 & -66 & -9.1 & 1690 \\
\hline 71 & Aux. Xotepingo 9-C & 42.6 & 0.25 & 13.4 & 48.3 & 0.4 & 204.9 & 142.4 & 16 & 671 & 31.3 & 0.9 & -67.2 & -9.3 & 1360 \\
\hline 74 & Purísima Democrática 2 & 23.6 & 0.04 & 29.9 & 38.3 & 0.03 & 543.8 & 366.6 & 358 & 1016.7 & 63.8 & 0.7 & -65.4 & -8.9 & 2503 \\
\hline 77 & Aux. Xotepingo 6-B & 40.5 & 0.1 & 25.4 & 40.8 & 0.09 & 500.6 & 278.7 & 574.1 & 691.3 & 47.5 & 1.1 & -58.4 & -7.7 & 1990 \\
\hline 79 & Purísima Iztapalapa 5 & 16.1 & 0.4 & 32.8 & 25.5 & 0.07 & 598.1 & 303 & 383.3 & 81.3 & 48.8 & 1 & -64.2 & -8.8 & 1990 \\
\hline
\end{tabular}




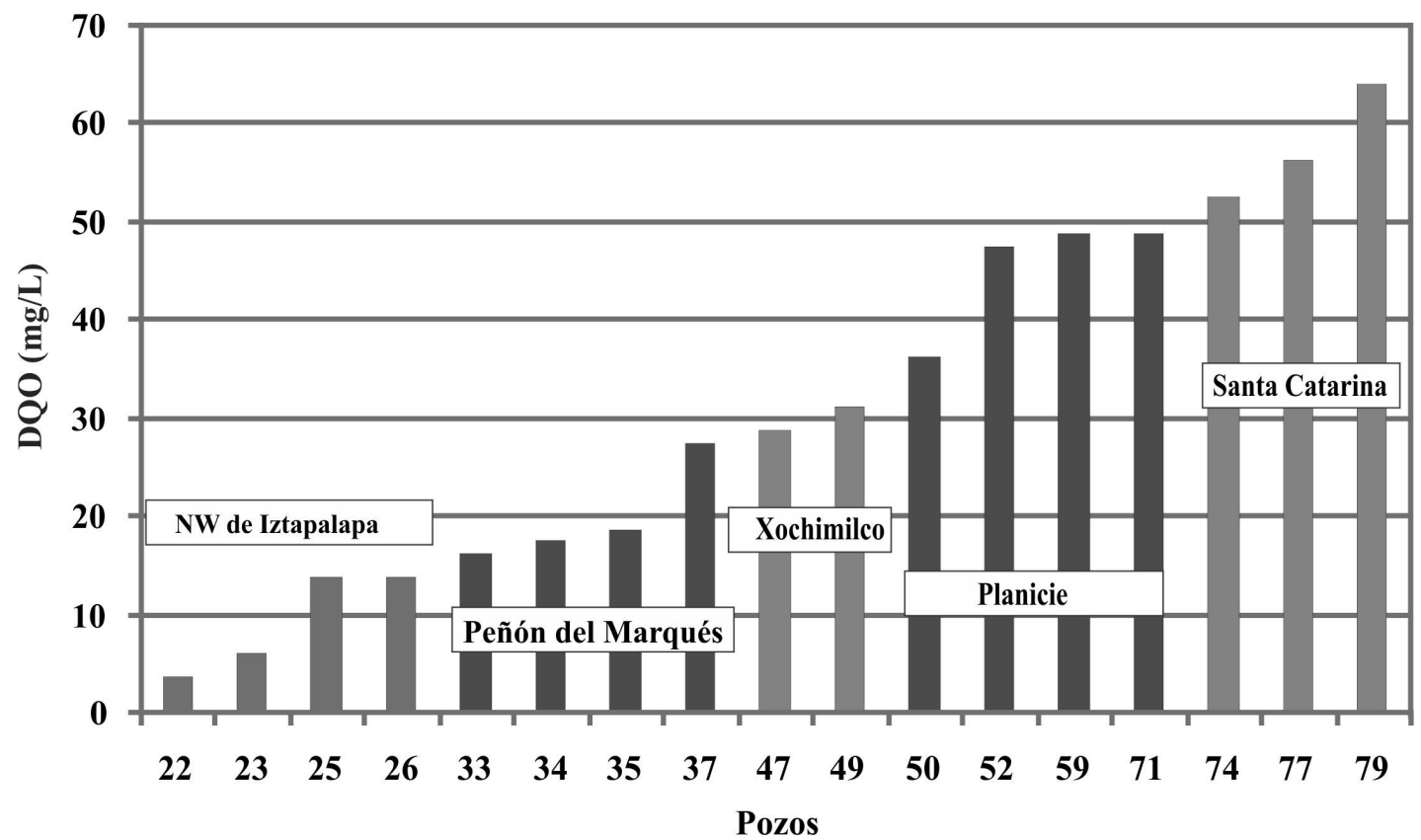

Figura 7. Concentraciones de DQO (mg/L) en agua subterránea de pozos de la delegación Iztapalapa. Se muestran las zonas en que se ha agrupado la delegación: zona NW, Peñón del Marqués, pozos próximos a Xochimilco, Planicie de la delegación y Sierra de Santa Catarina. La clasificación del agua de acuerdo a: DQO (mg/L) $\leq 3$, excelente; 3 -6, buena calidad; 6-30 aceptable; 30 - 120 contaminada, mayor a 120, fuertemente contaminada, CNA (2015).

continuación se encuentra el pozo 79 de la Sierra de Santa Catarina, luego el pozo 37 ubicado en Peñón del Marqués. En tanto que los pozos 59 y 26 localizados en la planicie y al NW de la delegación respectivamente, tienen los menores índices para óxidos y muestran la presencia de pirita, al igual que los pozos 35, 49, 59 y 71 que la presentan en equilibrio o en saturación, estos se localizan también en la planicie. Las concentraciones de Fe y Mn en el agua subterránea podrían tener su origen en la disolución de goethita y pirita contenidos en los sedimentos arcillosos del acuitardo (Díaz-Rodríguez, 2006), desde donde podrían pasar hacia el acuífero por inducción del bombeo intensivo y, en menor medida, en la disolución de los minerales primarios de origen volcánico ubicados en las zonas montañosas.

La magnitud de los IS obtenidos para el agua subterránea de los pozos tiene el siguiente orden, de mayor a menor: Planicie, Xochimilco, NW de la zona de estudio, Santa Catarina y Peñón del Marqués. Lo anterior permite explicar la turbiedad del agua subterránea, el mal sabor y aroma del agua de abastecimiento en la delegación. Los resultados obtenidos también se asocian con las condiciones redox a partir de la degradación de materia orgánica que produce fases oxidadas y fases reducidas de $\mathrm{Fe}$ y Mn, reducción de $\mathrm{SO}_{4}^{2-}$, incremento de la salinización y precipitación, procesos inducidos por la mezcla de diferentes rutas de flujo subterráneo y la inducción de agua salobre desde el acuitardo, por lo que se estima continuarán aumentando las concentraciones del agua subterránea y por ende, la presencia de estos minerales.

\subsection{Isótopos estables}

Los resultados obtenidos del análisis de isótopos estables en agua subterránea permitieron construir la Figura 9, donde se muestra la Línea Mundial de Aguas Meteóricas (LMAM) de acuerdo con Craig (1961) y la Línea Local de Agua Meteórica para la Cuenca de México, de acuerdo con Cortés et al. (1989). Las firmas isotópicas de las muestras colectadas describen una línea, en la cual las correspondientes al Peñón del Marqués y a Xochimilco son las más cercanas a la línea meteórica y las más empobrecidas en isótopos pesados. Las muestras correspondientes al NW de la zona y la planicie se ubican a continuación y en el extremo opuesto se ubican las pertenecientes a la Sierra de Santa Catarina. Todas las muestras en conjunto tienen la ecuación:

$$
\mathrm{y}=5.754 \mathrm{x}-13.58
$$

La pendiente de la recta que describen las firmas de las muestras indica que el agua subterránea ha tenido un proceso de evaporación, de acuerdo con Clark y Fritz (1997) que señala lo anterior para pendientes entre 4 y 6 . Para el área de estudio, lo anterior representa la mezcla de agua evaporada procedente del acuitardo, en diferentes proporciones con agua de toda la zona de estudio. La firma isotópica de la Sierra de Santa Catarina ubicada en el extremo, es producto de procesos diferentes a los acontecidos en el subsuelo. Un caso similar fue el identificado por Domínguez-Mariani (2005) para la firma de agua residual de Tecamachalco, Puebla. 
Tabla 2. Índices de saturación determinados con el software PHREEQC para el agua subterránea colectada en la delegación Iztapalapa.

\begin{tabular}{|c|c|c|c|c|c|c|c|c|c|}
\hline & & & Rodocrosita & Calcita & Siderita & Barita & Calcedonia & Cuarzo & $\mathrm{Fe}(\mathrm{OH})_{2} \cdot 7 \mathrm{Cl}_{3}$ \\
\hline Pozo & $\mathrm{CO}_{2}(\mathrm{~g})$ & $\mathrm{H}_{2} \mathrm{~S}(\mathrm{~g})$ & $\mathrm{MnCO}_{3}$ & $\mathrm{CaCO}_{3}$ & $\mathrm{FeCO}_{3}$ & $2 \mathrm{BaSO}_{4}$ & $3 \mathrm{SiO}_{2}$ & $3 \mathrm{SiO}_{2}$ & $4 \mathrm{Fe}(\mathrm{OH})_{2} \cdot 7 \mathrm{Cl}_{3}$ \\
\hline 22 & -2.3836 & -11.4079 & 1.2697 & 1.2422 & 0.052 & 0.1775 & 0.3457 & 0.7981 & 1.4429 \\
\hline 23 & -1.9541 & -70.2556 & 0.642 & 0.6037 & -3.2347 & -0.579 & 0.3079 & 0.7642 & 5.2909 \\
\hline 25 & -2.0846 & -12.1821 & 0.4814 & 0.9625 & 0.064 & -2.1444 & 0.316 & 0.7692 & 0.9899 \\
\hline 26 & -1.4083 & -5.6926 & 0.3086 & 0.7635 & -0.3055 & -0.6464 & 0.3 & 0.7516 & -0.3637 \\
\hline 33 & -2.3217 & -10.1668 & -0.1719 & 0.3384 & -1.0437 & -0.3575 & 0.1997 & 0.6497 & 0.0097 \\
\hline 34 & -2.4186 & -11.1458 & -0.3176 & 0.3431 & -1.5221 & -0.5069 & 0.1335 & 0.5835 & -0.3575 \\
\hline 35 & -2.2124 & -8.0911 & -0.6925 & -0.017 & -1.3566 & -0.3816 & 0.1739 & 0.6239 & -0.5768 \\
\hline 37 & -2.5116 & -12.1974 & -0.0893 & 0.4738 & -0.5152 & 0.0444 & 0.1858 & 0.6366 & 0.8392 \\
\hline 47 & -2.0052 & -67.017 & -2.3341 & -0.1141 & -2.6617 & -0.1554 & 0.2814 & 0.7377 & 5.5931 \\
\hline 49 & -2.1942 & -2.6914 & -1.5217 & -0.5542 & -3.8668 & 0.449 & 0.3045 & 0.7625 & -3.4436 \\
\hline 50 & -1.6486 & -65.0613 & -0.1313 & -0.0399 & -1.1022 & 0.922 & 0.2884 & 0.7407 & 6.867 \\
\hline 52 & -2.0193 & -4.9651 & -0.2265 & 0.1883 & -0.9511 & 0.7841 & 0.2388 & 0.6952 & -0.4589 \\
\hline 59 & -1.8819 & -6.2432 & 0.6825 & 0.574 & -0.0689 & 0.1839 & 0.284 & 0.7419 & 0.3497 \\
\hline 71 & -1.8487 & -6.2054 & 0.3216 & 0.388 & -0.2886 & -0.9882 & 0.2961 & 0.7557 & -0.0226 \\
\hline 74 & -2.3784 & -12.0156 & -0.1102 & 0.8571 & -0.3579 & 0.5735 & 0.1473 & 0.6017 & 1.089 \\
\hline 77 & -2.5604 & -11.733 & 0.1413 & 0.888 & -0.1749 & 0.3854 & 0.1114 & 0.5694 & 1.3885 \\
\hline \multirow[t]{2}{*}{79} & -3.5629 & -13.0962 & -0.6429 & -0.1922 & -0.2308 & 0.6008 & 0.055 & 0.5035 & 2.4987 \\
\hline & Magnesioferrita & Hematita & Magnetita & Greenalita & Goetita & Pirita & Hidroxilapatita & Piromorfita & $\mathrm{MnHPO}_{4}$ \\
\hline Pozo & $4 \mathrm{Fe}_{2} \mathrm{MgO}_{4}$ & $4 \mathrm{Fe}_{2} \mathrm{O}_{3}$ & $4 \mathrm{Fe}_{3} \mathrm{O}_{4}$ & $4 \mathrm{Fe}_{3} \mathrm{Si}_{2} \mathrm{O}_{5}(\mathrm{OH})_{4}$ & $4 \mathrm{FeOOH}$ & $4 \mathrm{FeS}_{2}$ & $5 \mathrm{Ca}_{5}\left(\mathrm{PO}_{4}\right)_{3} \mathrm{OH}$ & $5 \mathrm{~Pb}_{5}\left(\mathrm{PO}_{4}\right)_{3} \mathrm{Cl}$ & $5 \mathrm{MnHPO}_{4}$ \\
\hline 22 & -0.5323 & 4.2845 & 9.7537 & 3.827 & 0.9456 & -1.5228 & -999.999 & -999.999 & -999.999 \\
\hline 23 & 5.5075 & 11.5913 & 13.2551 & -7.3662 & 4.6048 & -107.83 & -999.999 & -999.999 & -999.999 \\
\hline 25 & -2.1654 & 3.2587 & 8.4232 & 2.9128 & 0.4338 & -3.7375 & 7.2719 & 6.9674 & 1.9723 \\
\hline 26 & -5.9409 & 0.2705 & 4.4245 & -0.269 & -1.0626 & 7.1545 & 5.2983 & 2.2461 & 1.9324 \\
\hline 33 & -3.8103 & 1.7238 & 6.0879 & 0.0441 & -0.3382 & -0.6603 & -999.999 & -999.999 & -999.999 \\
\hline 34 & -4.2985 & 1.1609 & 5.1436 & -1.2327 & -0.6196 & -2.7997 & -999.999 & -999.999 & -999.999 \\
\hline 35 & -5.4975 & 0.4793 & 4.4212 & -1.2742 & -0.9604 & 2.6688 & -999.999 & -999.999 & -999.999 \\
\hline 37 & -1.527 & 3.6295 & 8.6946 & 2.1778 & 0.6158 & -3.4625 & -999.999 & -999.999 & -999.999 \\
\hline 47 & 5.4582 & 12.2397 & 14.5277 & -5.5466 & 4.9291 & -101.329 & -999.999 & -999.999 & -999.999 \\
\hline 49 & -12.9953 & -5.8982 & -4.6623 & -8.5361 & -4.1375 & 10.3487 & 2.9448 & -28.2719 & 0.9561 \\
\hline 50 & 7.6925 & 14.5063 & 18.0862 & -1.9551 & 6.0565 & -96.7187 & -999.999 & -999.999 & -999.999 \\
\hline 52 & -6.2824 & 0.089 & 4.1017 & -0.4577 & -1.1463 & 8.8998 & -999.999 & -999.999 & -999.999 \\
\hline 59 & -4.622 & 1.673 & 6.3944 & 1.8794 & -0.352 & 7.3309 & 5.4681 & 4.6206 & 2.3291 \\
\hline 71 & -5.72 & 0.861 & 5.2933 & 1.1579 & -0.7555 & 6.9962 & 5.703 & 5.5876 & 2.3701 \\
\hline 74 & -1.6161 & 3.5192 & 8.5271 & 2.2009 & 0.5659 & -2.8989 & -999.999 & -999.999 & -999.999 \\
\hline 77 & -1.2998 & 4.0179 & 9.3118 & 3.2516 & 0.8204 & -1.8761 & -999.999 & -999.999 & -999.999 \\
\hline 79 & 2.0114 & 6.734 & 13.1871 & 5.9046 & 2.1645 & -3.7058 & 6.367 & 10.3856 & 1.5104 \\
\hline
\end{tabular}

\section{Conclusiones}

La explotación intensiva del agua subterránea que se ha llevado a cabo en toda la Cuenca de México ha producido particularmente en la delegación Iztapalapa hasta $63 \mathrm{~m}$ de descenso de los niveles piezométricos en el periodo 1967 - 2011. La dirección del flujo subterráneo determinada para el año 2011 muestra que en la delegación Iztapalapa confluye el flujo subterráneo tanto del norte de la delegación, de la Sierra de Santa Catarina y del sur, procedente de Xochimilco, lo que produce un proceso hidrogeoquímico de mezcla entre los diversos componentes. Adicionalmente se tiene que los depósitos volcánicos altamente fracturados en la Sierra de Santa Catarina permiten la relativamente rápida infiltración de agua residual hacia el acuífero, debido a que en esta zona el acuífero regional no tiene la cobertura del acuitardo. Otra componente es el flujo vertical descendente, inducido por el bombeo intensivo y procedente del acuitardo 


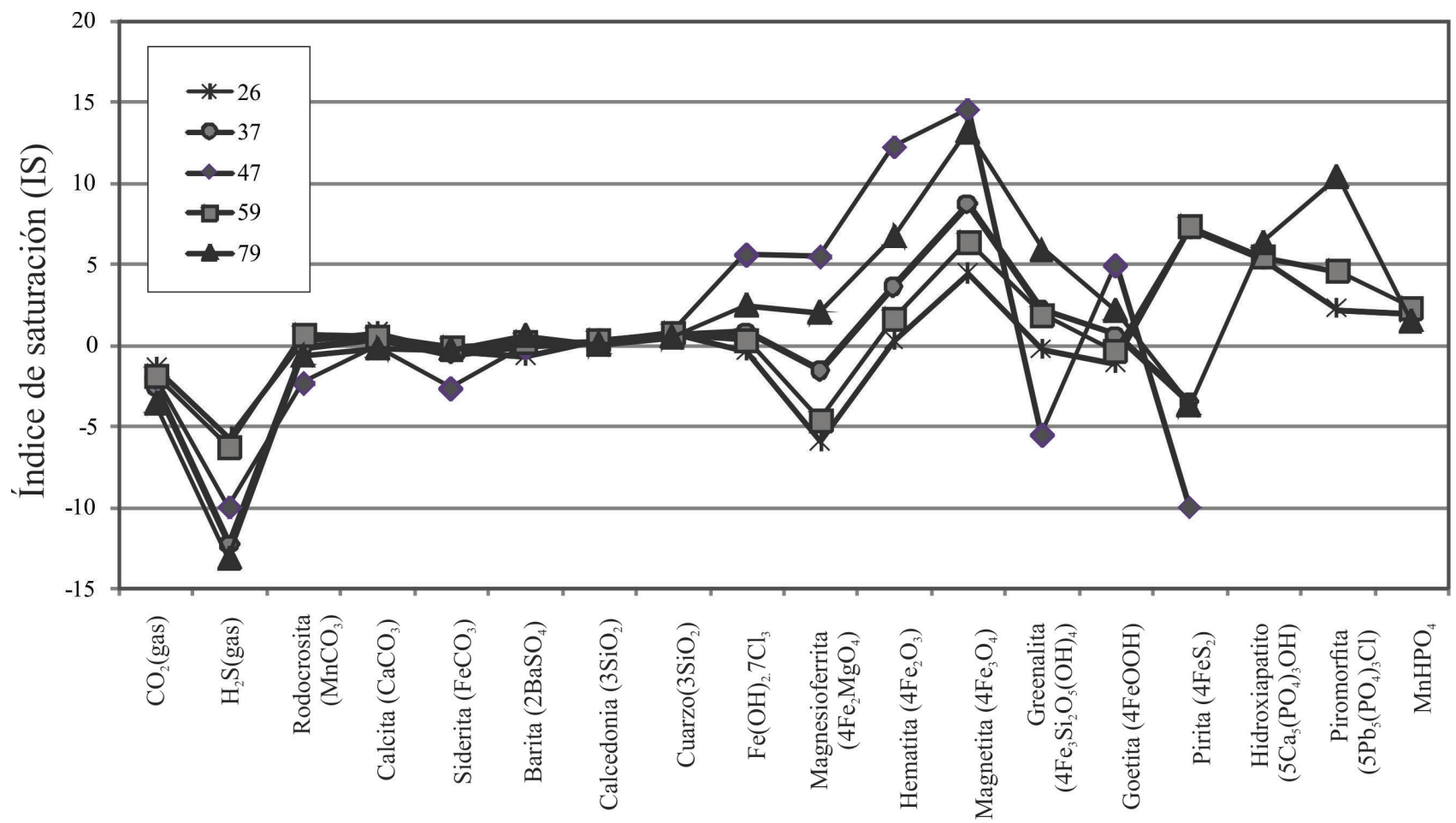

Figura 8. Índices de saturación de minerales en agua subterránea de la delegación Iztapalapa; el pozo 26 se ubica en la zona denominada Iztacalco, pozo 37 en el Peñón del Marqués, el 47 en Xochimilco, 59 en la Planicie, y el 79 en la Sierra de Santa Catarina.

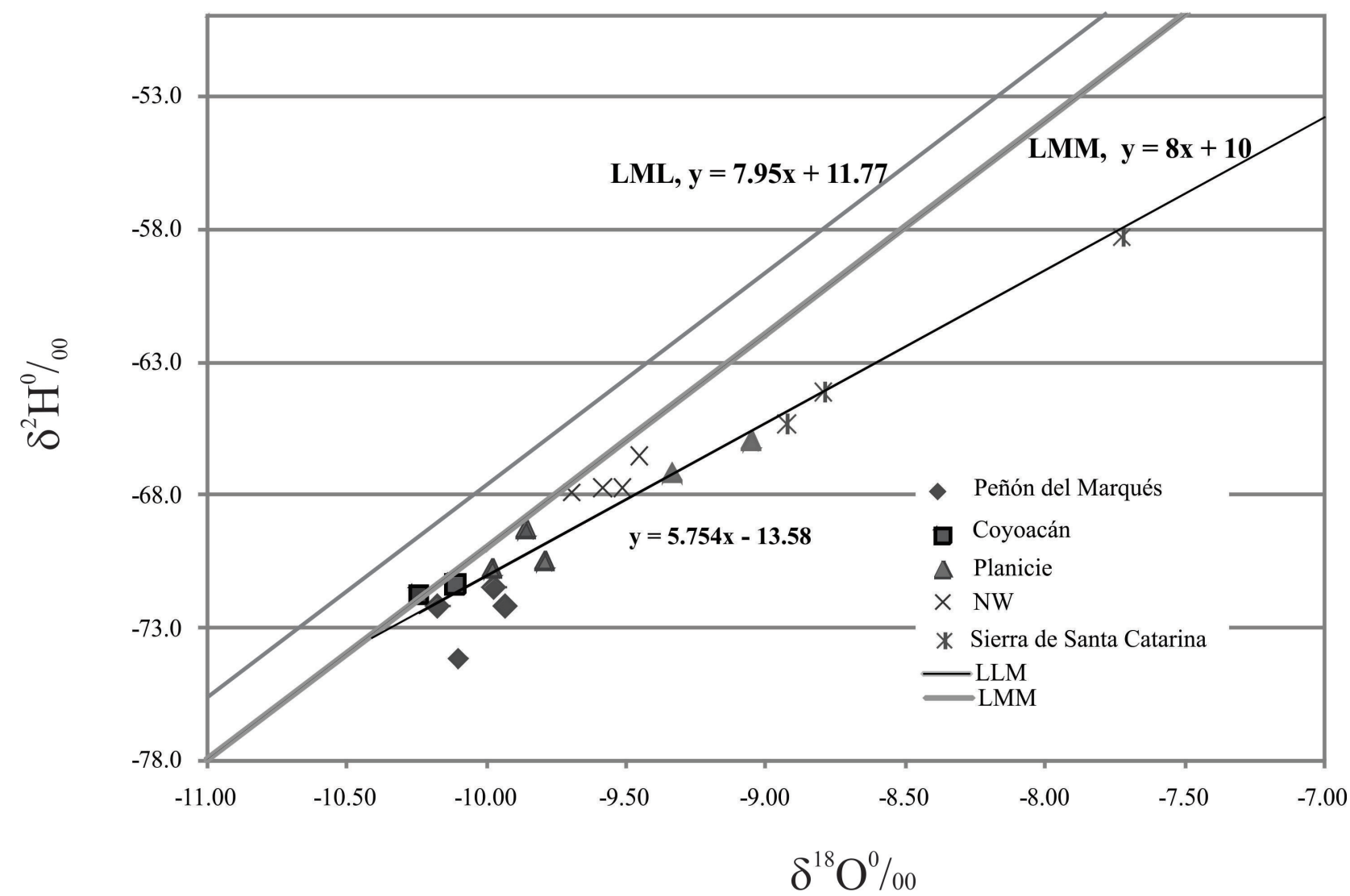

Figura 9. Diagrama $\delta^{18} \mathrm{O} v s . \delta \mathrm{D}$ para muestras colectadas en la delegación Iztapalapa. Se diferencia los pozos por cada zona en que se ha agrupado la delegación: zona NW, Peñón del Marqués, pozos próximos a Xochimilco, Planicie de la delegación y Sierra de Santa Catarina. La clasificación del agua de acuerdo a: DQO (mg/L) $\leq 3$, excelente; $3-6$, buena calidad; 6-30 aceptable; 30 - 120 contaminada, mayor a 120, fuertemente contaminada, CNA(2015). 
sobreyacente. Esta componente tiene un elevado contenido iónico, que produce un incremento de sales en el agua del acuífero regional.

Se determinó que el agua subterránea de la delegación tiene concentraciones elevadas de $\mathrm{Fe}^{2+}(0.004-0.64 \mathrm{mg} / \mathrm{L})$, $\mathrm{Mn}^{2+}(0.003-0.96 \mathrm{mg} / \mathrm{L}), \mathrm{Na}^{+}(91-598.1 \mathrm{mg} / \mathrm{L}), \mathrm{Cl}^{-}(59$ - $372.3 \mathrm{mg} / \mathrm{L}$ ), presencia de materia orgánica (expresada en términos de DQO, 3.75 - $63.8 \mathrm{mg} / \mathrm{L}$ ) y conductividad eléctrica en el intervalo de $620-2503 \mu \mathrm{S} / \mathrm{cm}$. Al comparar las concentraciones del agua subterránea del ión $\mathrm{Na}^{+}$con la NOM-127-SSA1-1994 (DOF, 2000) 10 pozos se encuentran fuera de la norma mexicana para agua potable (DOF, 2000) de 17 visitados; para el $\mathrm{Cl}^{-}, 7$ de 17 están fuera; para el $\mathrm{Fe}^{2+}$, 3 lo están; y para el $\mathrm{Mn}^{2+}$, 8 la superan.

A partir de las concentraciones de los parámetros medidos en campo y en laboratorio se calcularon los índices de saturación mediante PHREEQC, que indican la tendencia a precipitar óxidos ferromagnesianos, carbonatos, fosfatos y silicatos. Esto permite explicar los depósitos de color café a negro en la red de distribución de la demarcación y la turbiedad del agua extraída de pozos. Las condiciones reductoras del agua subterránea fueron reproducidas, mediante la presencia de gases como $\mathrm{H}_{2} \mathrm{~S}_{\text {y }} \mathrm{CH}_{4}$ relacionados con la degradación de materia orgánica que se encuentra de forma singenética en el acuitardo. Procesos asociados son la reducción de sulfatos y denitrificación. De esta manera, se explica el intenso aroma que presenta el agua subterránea de la zona de estudio.

Mediante el análisis de iones mayores e isótopos estables, se definieron cinco áreas: una, el Peñón del Marqués que es una zona con agua subterránea de menor contenido iónico asociada a rocas piroclásticas; dos, Sierra de Santa Catarina, donde la composición original ha sido alterada debido a infiltración de agua residual por lo que ahora tiene mayor contenido iónico especialmente de $\mathrm{Na}^{+}$, $\mathrm{Cl}^{-}, \mathrm{SO}_{4}^{2-}, \mathrm{Fe}^{2+}, \mathrm{DQO}$; tres, la zona próxima a Xochimilco que tiene tanto la influencia del acuitardo como de la recarga de la Sierra Chichinautzin, pero aún conserva contenido iónico bajo cuya composición se observa en algunos pozos de la planicie; cuatro, ubicada al NW de la delegación, que tiene la influencia del acuitardo contribuye a incrementar la mineralización del agua debido al elevado contenido de salinidad que contiene; y cinco, la planicie de la delegación en donde la unión de estos componentes produce agua subterránea con elevado contenido iónico.

Se ha comentado frecuentemente que los efectos asociados con la explotación intensiva en la Cuenca de México son subsidencia, fracturamiento y descenso de niveles piezométricos. Se demuestra que el deterioro de la calidad del agua también se desarrolla a la par en la zona, tanto como un efecto secundario al inducir flujo desde el acuitardo y la infiltración de agua residual en rocas fracturadas. En conjunto, se infiere un proceso continuo de deterioro del agua subterránea que reducirá aún más la disponibilidad del recurso hídrico en la Cuenca de México

\section{Agradecimientos}

Los autores agradecen los comentarios y aportaciones realizadas por los revisores del artículo, las que permitieron mejorarlo en gran medida. También agradecen el entusiasta apoyo en campo y en gabinete de Juan Antonio Bernal Villa, Fredy Martínez Mijangos, Daniel Cariño Mendoza, Alejandro Rodríguez Pérez y de Manuel Frías Vargas. También se contó con el invaluable trabajo en laboratorio de las Ings. Judith L. Castillo García, Adriana Reyes Regalado y de la M. en C. Carolina Muñoz Torres. La información técnica de pozos fue proporcionada por la amable colaboración del Ing. Alfonso Hernández López y del Ing. Fernando González López de la delegación Iztapalapa, a quienes se les agradece su atención. Con una mención especial se extiende un agradecimiento al Dr. Oscar Escolero Fuentes por los valiosos comentarios realizados al presente.

\section{Referencias}

American Public Health Association, American Water Works Association, Water Environment Federation (APHA, AWWA, WPCF), 1992, Standard Methods for examination of Water and Wastewater: Washington, D.C., USA, American Public Health Association, Water Pollution Control Federation, $17^{\text {th }}$ Edition.

Arango-Durán, A., Lara-Medina, C., 2005, Delegación Iztapalapa: Perfil Sociodemográfico, en Análisis sobre la violencia social en la Delegación Iztapalapa, Instituto Ciudadano de Estudios sobre la Inseguridad, A.C. (ICESI)-Center for U.S.-Mexican Studies UCSD, 41 p., disponible en < http://www.iztapalapa.df.gob.mx/pdf/ SIBDSI/DIAGNOSTICO/iztapalapa_perfil_sociodemografico.pdf $>$, consultado 15 de agosto de 2015.

Cabral-Cano, E., Dixon, T.H., Sánchez, O., 2002, Análisis de subsidencia en la Cd. de México mediante InSAR y GPS, (resumen), en DelgadoArgote, L.A. (ed.), III Reunión Nacional de Ciencias de la Tierra: Puerto Vallarta, Jalisco, México, Sociedad Geológica Mexicana, 4-8 noviembre 2002, $424 \mathrm{p}$.

Carrillo, N., 1947, Influence of artesian wells in the sinking of Mexico City, Comisión Impulsora y Coordinadora de la Investigación Científica, Anuario 47, en Volumen Nabor Carrillo, 7-14, Secretaria de Hacienda y Crédito Público, México, 1969.

Clark, I.D., Fritz, P., 1997, Environmental Isotopes in Hydrology: Boca Raton, Lewis Publishers, 328 p.

Coleman, M.L., Shepard T.J., Durham, J.J., Rouse, J.E., Moore, G.R., 1982, Reduction of water with zinc for hydrogen isotope analysis: Analytical Chemistry, 54, 993-995.

Comisión Nacional del Agua (CNA), 2015, Indicadores de calidad del agua. Escala de clasificación de calidad del agua. Demanda Química de Oxígeno (DQO), disponible en <http://www.conagua.gob.mx/ CONAGUA07/Contenido/Documentos/DQO.pdf>, consultado 25 de agosto de 2015.

Cortés, A., Arizábalo, R.D., Rocha, M.R., 1989, Estudio hidrogeoquímico de manantiales en la Cuenca de México: Geofísica Internacional, $28,265-282$.

Craig, H., 1961, Isotopic Variations in Meteoric Waters: Science New Series, 133, 1702-1703.

DI (Delegación Iztapalapa), 2007. Diagnóstico de la problemática del agua en la Delegación Iztapalapa, D.G. Servicios Urbanos, Delegación Iztapalapa, Gobierno del Distrito Federal, 2 de marzo de 2007, disponible en <http://www.aldf.gob.mx/archivo-d58b4c42b30d 13de6722aa2cc16b3720.pdf>, consultado 25 de agosto de 2015. 
Díaz-Rodríguez, J.A., 2006, Los Suelos Volcánico-Lacustres de la Ciudad de México: Revista Internacional de Desastres Naturales, Accidentes e Infraestructura Civil, 6, $44 \mathrm{p}$.

Díaz-Rodríguez, J.A., Leroueil, S., Alemán, J.D., 1992, Yielding of Mexico City clay and other natural clays: Journal of Geotechnical Engineering, 118, 981-995.

DOF (Diario Oficial de la Federación), 2000, Modificación a la Norma Oficial Mexicana NOM-127-SSA1-1994, Salud ambiental. Agua para uso y consumo humano. Límites permisibles de calidad y tratamientos a que debe someterse el agua para su potabilización, 22 de noviembre de 2000, 73-79.

Domínguez-Mariani, E., 1996, Geoquímica del Agua Salina del Acuitardo Lacustre y Riesgo de Contaminación al Acuífero Subyacente que abastece a la Ciudad de México: México D.F., Facultad de Ingeniería, Universidad Nacional Autónoma de México, tesis de maestría, 122 p.

Domínguez-Mariani, E., 2005, Geoquímica de Tecamachalco, Puebla, México: México, Posgrado en Ciencias de la Tierra, Universidad Nacional Autónoma de México, tesis doctoral, 178 p.

Edmunds, W.M., Carrillo-Rivera, J.J., Cardona, A., 2002, Geochemical Evolution of Groundwater beneath México City: Journal of Hydrology, 259, 1-24.

Epstein, S., Mayeda, T., 1953, Variation of ${ }^{18} \mathrm{O}$ content of waters from natural sources:Geochimicaet Cosmochimica Acta, 4, 213-224.

Foster, S., Hirata, R., Gomes, D., D'Elia, M., Paris, M., 2007, Protección de la calidad del agua subterránea:Washington, D.C., Banco Mundial, $128 \mathrm{p}$.

Goren, O., 2009, Geochemical Evolution and Manganese Mobilization in Organic Enriched Water Recharging a Calcareous-Sandstone Aquifer; Clues from the Shafdan Sewage Treatment Plant: Jerusalem, The Ministry of National Infrastructures, Geological Survey of Israel, Report GSI/12/09, Julio de 2009, 187 p.

Hackley, K.C., Liu, C.L., Trainor, D., 1999, Isotopic identification of the source of methane in subsurface sediments of an area surrounded by waste disposal facilities: Applied Geochemistry, 14, 119-131.

Herndon, E.M., Jin, L., Brantley, S.L., 2011, Soils Reveal Widespread Manganese Enrichment from Industrial Inputs: Environmental Science \& Technology, 45, 241-247.

Huizar-Álvarez, R., Carrillo-Rivera, J.J., Ángeles-Serrano, G., Hergt, T., Cardona, A. 2004, Chemical Response to Groundwater Extraction Southeast of Mexico City: Hydrogeology Journal, 12, 436-450.

Instituto Nacional de Estadística y Geografía (INEGI), 2015, Iztapalapa, Distrito Federal, México en cifras, disponibe en $<\mathrm{http} / / / \mathrm{www} 3$. inegi.org. $\mathrm{mx} /$ sistemas $/$ mexicocifras $/$ default.aspx? $=9>$, consultado 25 de agosto de 2015.

Izazola, H., 2001, Agua y Sustentabilidad en la Ciudad de México: Estudios Demográficos y Urbanos en la Ciudad de México, 47, 285-320.

Jaramillo, A., Sánchez, O., 2002, El hundimiento de la Cd. de México en el periodo 1995-2001 observado con GPS (resumen), en DelgadoArgote, L.A. (ed.), III Reunión Nacional de Ciencias de la Tierra: Puerto Vallarta, Jalisco, México, Sociedad Geológica Mexicana, $270 \mathrm{p}$.
Montiel-Palma, S., Armienta-Hernández, M.A., Rodríguez-Castillo, R., Domínguez-Mariani, E., 2014, Identificación de zonas de contaminación por nitratos en el agua subterránea de la zona sur de la Cuenca de México: Revista Internacional de Contaminación Ambiental, 30, 149-165.

Rudolph, D.L., Cherry, J.A., Farvolden, R.N., 1991, Groundwater flow and solute transport in fractured lacustrine clay near Mexico City: Water Resources Research, 27, 2187-2201.

Sistema de Aguas de la Ciudad de México (SACM), 2009, Diagnóstico de las causas que originan la contaminación del acuífero de la zona sur oriente del D.F. y sus alternativas de solución: Estudio elaborado por Lesser y Asociados, S.A. de C.V., Querétaro, México, 93 p.

Terzaghi, K., 1925, Principles of soil mechanics: IV settlement and consolidation of clay: Engineering News-Record, 95, 874-878.

United States Geological Survey (USGS), 2014, PHREEQC (Version 3)--A Computer Program for Speciation, Batch-Reaction, OneDimensional Transport, and Inverse Geochemical Calculations: software de acceso libre, Lakewood, Colorado.

Vargas-Cabrera, C., 1995. Distribución de la conductividad hidráulica en el acuitardo lacustre de la Subcuenca de Chalco, D.F. y Edo. de México: México D.F., Facultad de Ingeniería, Universidad Nacional Autónoma de México, tesis de licenciatura, $50 \mathrm{p}$.

Vargas-Cabrera, C., 2001, Propiedades y Comportamiento Hidráulico del Acuitardo Lacustre de la Ciudad de México: México D.F., Facultad de Ingeniería, Universidad Nacional Autónoma de México, tesis de maestría, $87 \mathrm{p}$

Vargas, C., Ortega-Guerrero, A., 2004. Fracture hydraulic conductivity in the Mexico City clayey aquitard: Field piezometer rising-head tests: Hydrogeology Journal, 12, 336-344.

Varner, D., Skipton, S., Jasa, P.J., Dvorak, B., 1996, G96-1275 Drinking water: sulfates and hydrogen sulfide, Historical Materials from University of Nebraska-Lincoln Extension. Paper 1425, 7 p., disponible en $<\mathrm{http}$ //digitalcommons.unl.edu/extensionhist/1425>, consultado 25 de agosto de 2015.

Vázquez-Sánchez, E., 1995, Modelo Conceptual Hidrogeológico y Características Hidráulicas del Acuífero en Explotación en la Parte Meridional de la Cuenca de México: México D.F., Instituto de Geofísica, Universidad Nacional Autónoma de México, Tesis de Maestría, $187 \mathrm{p}$

Vennemann, T.W., O'Neil, J.R., 1993, A simple and inexpensive method of hydrogen isotope and water analyses of minerals and rocks based on zinc reagent: Chemical Geology, 103, 227-234.

Manuscrito recibido: Abril 15, 2014.

Manuscrito corregido recibido: Diciembre 2, 2015.

Manuscrito aceptado: Febrero 5, 2015. 